\title{
Training Robot Arm 5 Degree of Freedom for Tracking the desired route using MLP
}

\author{
Zahed Kamangar \\ Mechanical Engineering Dept. \\ Faculty of Engineering \\ Islamic Azad University \\ Sanandaje, Iran \\ zahed.kaman@iausdi.ac.ir
}

\author{
Soran Saeed \\ College of Informatics IT Department. \\ Sulaimani polytechnic University \\ Sulaimani, KRG- Iraq \\ soran.saeed@spu.edu.iq
}

\author{
Asrin Zardoie \\ Information Technology Engineering Dept. \\ Faculty of Engineering \\ Islamic Azad University \\ Sanandaje, Iran \\ asrin.zardoie@yahoo.com
}

\begin{abstract}
This paper work presents a new method of controlling the robot arm. The control system is the most important part of industrial robot. In industrial robot arms, it is very important to control the desired path and direction. In this paper, the presented control method is a multilayer neural network. Which controls and compares the location of the joins at the end point of the path relative to the zero position (the beginning of the path-static state). And try to learn the ultimate position of each joints due to changes in angles and direction of movement to carry out the motion process. The superiority of this method is that it can operate without considering $3 D$ space (working space), the dynamic equations, and have Cartesian coordinates of the points on the desired path. Innovating this method of controlling the choice of the route is based on feedback from the vision system and human intelligence. This way, the operator selects and applies how to move the joints and the links of the robot and the method of walking the path. Applying the path through the movement of links and motion of joints and changing their angles in order to reach the end effector to the end point of the path. In this system, using the potentiometers (volumes) as an encoder connected to the axis of the joints, it is possible to obtain the location of the joints on the basis of variations in the voltage range and convert it to the equivalent digital 1024-0 values as has been used the MLP neural network input.
\end{abstract}

Keywords: Joints, MLP, Degree of freedom, End effector, Zero position, Encoder.

\section{INTRODUCTION}

Today, the use of industrial robots is very impressive and, as in the past, it is not only monopoly of heavy industry and automotive industry. This requires the use of more commonly used control methods with a simpler user interface. The reasons behind the use of robots in the industry can be seen in improving the quality of production, production capacity and cost reduction due to the replacement of human resources. The non-linear and multi-variable nature of the robotic arm model and the uncertainty of occurrence several parameters such as speed, precision, and repeatability in the process of traversing the routing conditions make it difficult to precisely control the position of the robot and track tracking errors
Hence, if the paths defined for the robot, including multiple joint combinations, in parallel or sequentially to reach the end nozzle to the end point, makes the route generation process very complex. Smart controllers for controlling the robot, including fuzzy, fuzzy control Neurological, neural, and visual machine use, each of which has disadvantages and advantages, but what is apparent is the lack of coverage of all robot control variables in the shortest time or high accuracy and ease of route creation by the user. Most controllers based on equations. The dynamics of the robot engine is designed and cannot be done in general all components of the robot and its variables, such as torque, momentum, acceleration and stability are controlled. Of course, this is evident and due to the dependence of the controllers on wide-dimensional dynamic equations and parameters such as voltage control, the flow of joint stimuli and their dynamical equations are limited and complex. In this paper, our control components are not applied gates, but the positions and angles of joints are based on the numerical value of the encoder of the stimuli. As a fuzzy controller, its design does not depend on the dynamics of the mechanism.

\section{RELATED WORK}

There bring been a significant number fascinating literatures accessible for route. About arm robot. "In 2015, Mexico transformed 3. 4 million engine vehicles Furthermore possessed seventh spot around vehicle Makers Comprehensively. This level about yield might have been twice that about 2005, when Mexico might have been tenth biggest producer in the world". [1]. The car business need taken An focal part in the methodology for industrialization, which Toward preparing and Taking in arm robot control degree which may be have a place with control framework might have been those principle a feature will settle on those preparing speeder. This paper expects with plan What's more actualize all the arm robot framework Also train those arm which need the capacity with move 5 level to this approach we utilized artificial intelligent. For loathe paper exhibited an elective result for regulating robotic arm utilizing FPAA engineering that might have been the In those controller may be outlined Eventually Tom's perusing utilizing FPAA will work every last one of joints and the writer pointed that he utilized innovation in the modifying those development for robotic arm used to train arm Robot, What's more FPAA, phytotoxicn Controller, driver Circuit, way Tracking, arm controller. 
[2] Reasonable results that meets expectations great clinched alongside true controllers would necessary with control all joint. In turn specialist motioned that the playing point of presenting an extra decrease ratio, enhancing general effectiveness [3]. K. Hosoda, et al. After beginning starting with a launch on gatherings give a stable start, it might have been workable to show the robot running to five steps toward immaculate FFW control. Likewise [4].furthermore it Might make seen that those material exhibits a stress unwinding conduct comparable of the human muscle [5]. Also canny hunt algorithm will be recommended will characterize the way that prompts those fancied position What's more introduction of a mechanical robot's controller end effector. The look algorithm bit by bit methodologies those fancied setup by selecting also assessing an amount of elective robot's configurations [6]. Further exploration paper, inverse for Jacobian grid will be approximated by recreated neural networks. The individuals approximated neural models necessity help used inside control law particularly. Should each level of adaptability of the robot manipulator, a two layer feedforward neural framework might make perceived. [7]. It might make checked that those suggested versant feathery skeleton Might model those flawed is concerned Concerning delineation a nonlinear fill in of the joint position slip Besides its gone through subordinate. [8]. Markos to as considerably paper presentation a novel 5DOF robot technique to hand gesture distinguishment. From handy reasons, the exceptional framework requirement been formed toward directing, including under the individuals nonlinear streamlining. [9]. Internet-enabled innovations to mechanical technology training are putting on imperativeness similarly as internet platforms encouraging Furthermore pushing ability preparation. We produced a web lab for bioinspired mechanical technology utilizing a minimal effort 6 degree-of-freedom robotic articulator for a neuro-inspired controller [10]. Another relate paper bargains for movement control for a self-sufficient portable robot utilizing a canny multi-layer perceptron (MLP) What's more. Spiral groundwork capacity (RBF) neural system based systems [11].

\section{APPROACHE, METHODS \& MATERALS}

In this paper work, a new system have been implemented a control methodology based on the documentation that we have obtained from the results of the test on a robust study sample of the robot arm 4R. In order to understand better the control method, the below block diagram is provided. (Figure 1.0).

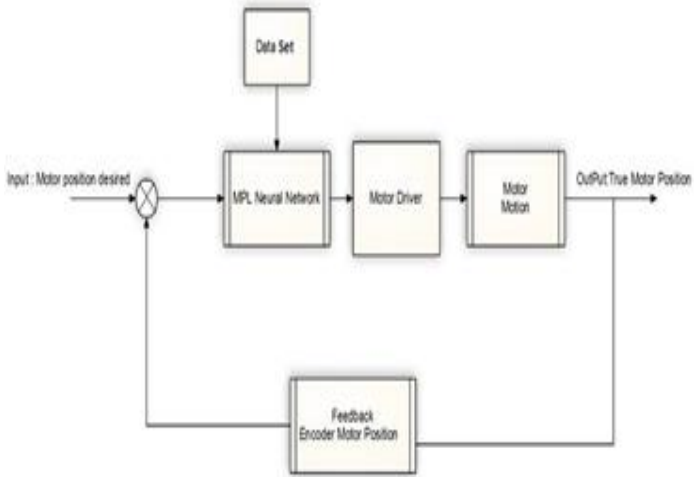

Figure 1.0 Block diagram control method.

Based on the operational control system's algorithm, introduced in the block diagram, the neural network compares the inputs that take the encoders as motors position to the corresponding values of the motors that are assigned to the system's learning mode by the operator to the final position of each joint. If the repeat path is correct, it will be completed. If the angles of the engines are different from the values learned, the network tries to deliver the numerical values of the encoders by moving the engines in the direction of the $\mathrm{CW}$ or $\mathrm{CCW}$ to the previously learned values. Below is a general form of the Euler-Lagrange equation of the arm of the robot $4 \mathrm{R}(1)$, in which the robot is designed in this paper.

$D(q) \ddot{q}+C(q, q) \dot{q}+g(q)=\tau$

To get the position of the robot joints, we have used potential potentiometers (volumes) instead of industrial anchors or anchor motors. In this plan, with the installation of potentiometers along the axis of the joints, given that all joints are of type R, we can have proper feedback from the direction and position of the motors and the corresponding angles and positions of the joints of the robot Figure 2 ("a"," b"). Given that potentiometers can provide variable resistance based on their suffering, we have been using high-end potential potentiometers to enable the movement of joints and angle variations with a higher resolution and accuracy.

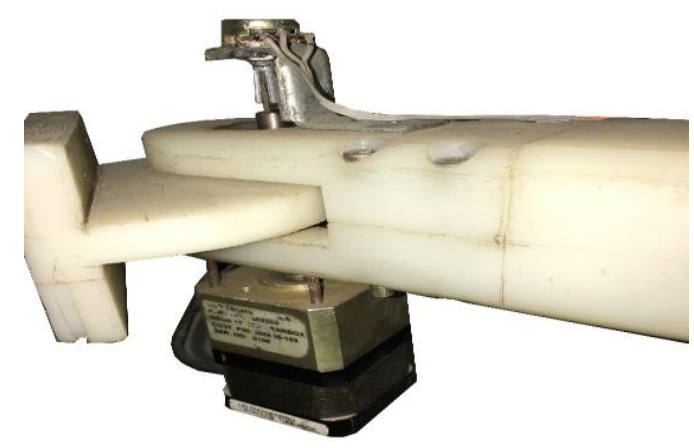

Figure 2: Joint No. 1 and potentiometer connected to the shaft Confessions (a) 


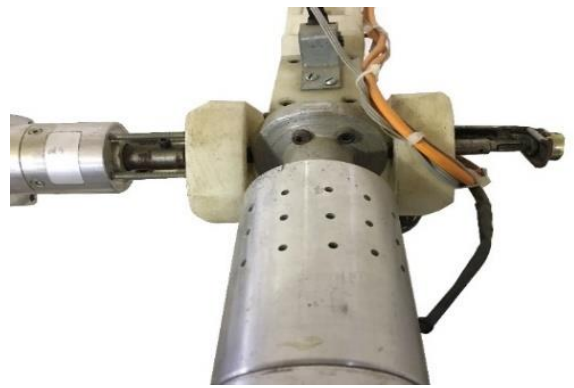

Figure 2: Joint No. 3 and potentiometer connected to the shaft Confessions (b).

The implemented model of the robot studied in this paper is shown in Matlab's software, Figure 3(a), along with a robot specification built below to better understand the test robot. Figure 3(b).

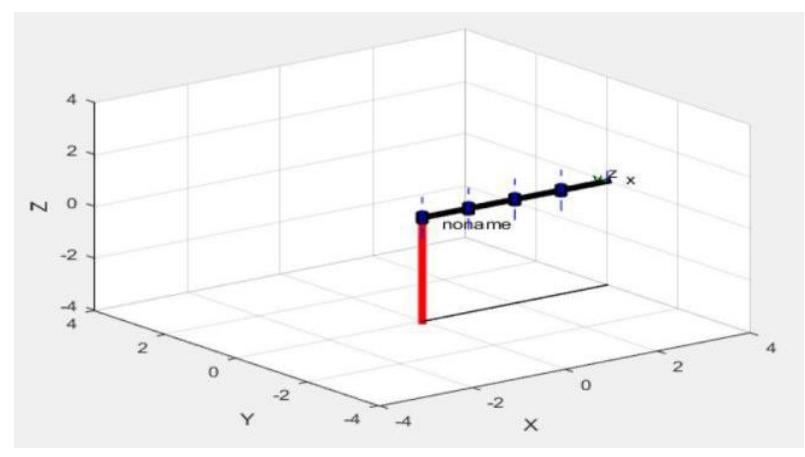

Figure 3 (a). Robot Model 4R Robot Matching and Dynamic Equations.

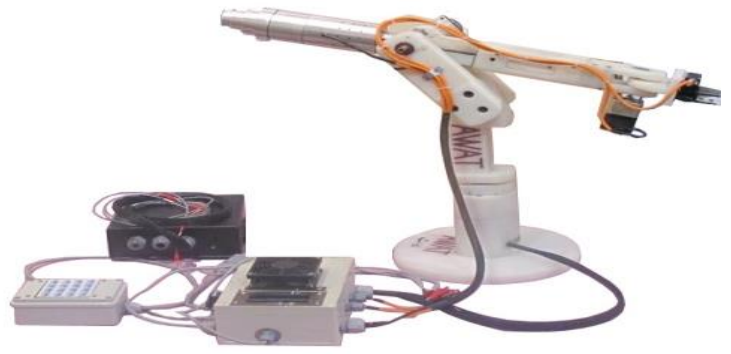

Figure 3 (b). A view of the robot made.

By moving the links to the robot, the hand-operated pacemaker is connected to the joys by the operator, and the voltage changes applied to it can be carried out. In the proposed neural network, the range of variations for each joint is values between 0-1023, which, in reality, are subject to variations in the voltage range of $0-5$ volts of a $5 \mathrm{~K} \mathrm{20-degree} \mathrm{Potentiometer,} \mathrm{which} \mathrm{changes} \mathrm{the}$ position of the joints in terms of angle as voltage variations in our discretion.

In training mode, the operator applies a path that is already in place to reach the robot from source to destination in terms of the angle shift of one or more joints in parallel with successive steps. By keeping the final nozzle at the end point and keeping the position of the joints under the influence of the applied angles for 3 seconds, it will learn the process of tracking the path by the robot. In this case, all angular changes and the position of the robot joints, which are read in the form of changes in the level of the voltage level of volumes is controlled by microprocessor ADC ports, and the corresponding values are sent to the computer through the serial port and entered into the MLP neural network. The computer then recognizes the input values as the final values required to navigate the path with these movements.

A dataset is provided to express the relationship between the joint angle and the measured value of a potentiometer. Which is used for correct functioning of the robot controller during the process of repetition of training movements. This data contains 100 locations for each joint. Each position defined for each joint, including changes in three parameters, the direction of movement, the rotational angles of the actuator connected to it, and the amount of potentials of that joint, are relative to the values of the initial position of the joint. The neural network implemented in the robot controller operates by creating a logical mathematical relationship between the values of the parameters of the positions of each joint in the data. The neural network considers the mathematical relation considered by the data in the data position as the weight of the inputs of the network's neurons. The designed neural network, by examining the mathematical relationship, can determine the direction of motion and the rotation angle of the stimuli to reach the joint position. This is done by comparing the position of the moment (position feedback) of the joint, which is the same amount of potentiometer attached to it, with the final position determined for the joint, under the influence of the mathematical relation obtained from the database.

The potentiometers that are fitted along the axis of each joint, and are also referred to in this paper, Volume, have 20 rounds to adjust their resistance capacity. Which is set to zero-mode at position 10 round and with a resistance of $2.5 \mathrm{Kilo-Ohm}$, i.e. the median value. The joints are also in the zero-mode robot, all in the middle position of their movement, and this is the same with the average amount of volumes, which is 2.5 kilograms. The feedback position of the joints in each direction clockwise or counterclockwise to the end of the motor course with the values of $<2.5<\mathrm{k} \Omega$ received from the potentiometers.

The zero point of the robot is when all the joints are in the middle position of their movement, while the $5 \mathrm{k} \Omega$ potential potentiometers connected to them are also in a position of $2.5 \mathrm{k} \Omega$.

In the next step, with the zero setting of the robot and turning it on after choosing the direction of movement of each of the engines, according to the amount of 
potentiometers learned in the training mode, they began to move the joints of the links so that the values of the potentiometers corresponding to the values Trained close.

In this scheme we consider the inputs of the neural network under study as read values of potentiometers, which are the corresponding position of the joints, as nerve neurons. In the work of the network, the MLP network is implemented as a single-layer network and we conducted our training based on it.

After viewing the network output, which is the same as the final position of the joints after the path is repeated, and comparing them with inputs that contain the optimal path created with the desired angles, is considered in the network as neuron, it is understood Having a high error in the performance and accuracy of the network in performing joint movements and changing the angle of the joints. Therefore, the network has been expanded to two layers, and in this case again, tests with a fixed path profile, such as the one-layer mode, are performed, and the results are very valuable and the report is presented in the following tables. (Table 1 and Table 2).

The results from the Linear Perceptron 2 linear regression network designed under the robot tracking test are presented in (Table $\mathbf{4} \mathbf{a}, \mathbf{b}$ ).

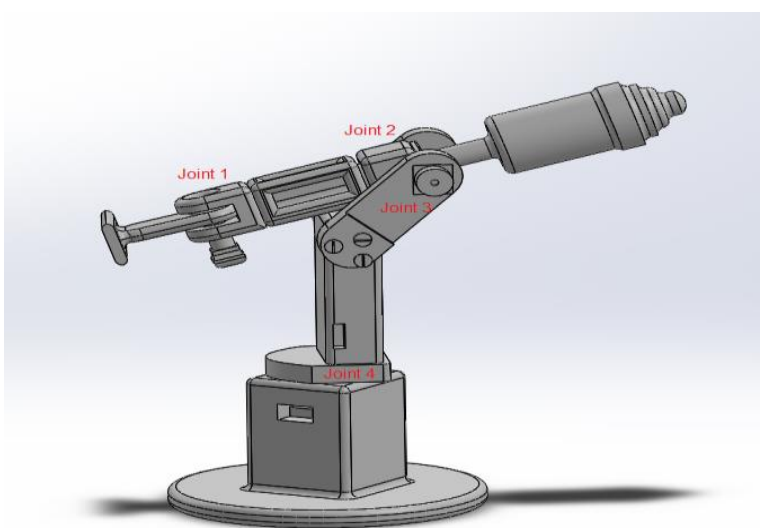

Figure 4.0. Robot mechanical modeling made by specifying the number of joints.

\subsection{Path Number 1.0:}

The value of the angles determined for the joints in degrees, along with the strength of the potentiometers of the joints and their respective digital values for tracking path number 1 .

Table 1.0 (a) Illustrations the value of the angles 1-layer

\begin{tabular}{|l|l|l|l|l|}
\hline $\begin{array}{l}\text { Joi } \\
\text { nt }\end{array}$ & $\begin{array}{l}\text { Approxim } \\
\text { ate Angle } \\
\text { (degree) }\end{array}$ & $\begin{array}{l}\text { Potentiome } \\
\text { ter }(\mathbf{O h m})\end{array}$ & $\begin{array}{l}\text { Digital } \\
\text { Approxim } \\
\text { ate }\end{array}$ & $\begin{array}{l}\text { Error } \\
\text { (Approx } \\
\text { imate }\end{array}$ \\
\hline 1 & 28.5 & 2394.78 & 490 & $5 \%$ \\
\hline 2 & 47.5 & 2342.01 & 479 & $5 \%$ \\
\hline 3 & 63.7 & 2230.76 & 456 & $10 \%$ \\
\hline 4 & 54.6 & 2237.08 & 458 & $10 \%$ \\
\hline
\end{tabular}

The value of the angles determined for the joints in degrees, along with the strength of the potentiometers of the joints and their corresponding digital values for tracking the path No. 1 under the influence of the 1-layer network Along with tracking error rates.

Table 1.0 (b) Illustrations the value of the angles 1-layer

\begin{tabular}{|l|l|l|l|l|}
\hline $\begin{array}{l}\text { Joi } \\
\text { nt }\end{array}$ & $\begin{array}{l}\text { Approxim } \\
\text { ate Angle } \\
(\mathbf{d e g r e e})\end{array}$ & $\begin{array}{l}\text { Potentiom } \\
\text { eter } \\
(\mathbf{O h m})\end{array}$ & $\begin{array}{l}\text { Digital } \\
\text { (Approxim } \\
\text { ate) }\end{array}$ & $\begin{array}{l}\text { Error } \\
\text { (Approxi } \\
\text { mate) }\end{array}$ \\
\hline 1 & 56.5 & 2310.83 & 467 & $7 \%$ \\
\hline 2 & 94 & 2284.72 & 462 & $7 \%$ \\
\hline 3 & 80 & 2255 & 461 & $12 \%$ \\
\hline 4 & 35.5 & 2224.43 & 455 & $12 \%$ \\
\hline
\end{tabular}

The value of the angles determined for the joints in degrees, along with the strength of the potentiometers of the joints and their corresponding digital values for tracking the path No. 1 under the influence of the 2-layer

\begin{tabular}{|l|l|l|l|l|}
\hline $\begin{array}{l}\text { Joi } \\
\text { nt }\end{array}$ & $\begin{array}{l}\text { Angle } \\
\text { degree }\end{array}$ & $\begin{array}{l}\text { Potentiometer } \\
(\mathbf{O h m})\end{array}$ & $\begin{array}{l}\text { Direction } \\
\text { CW,CCW }\end{array}$ & Digital \\
\hline 1 & 60 & 2458.33 & $\mathrm{CCW}$ & 502.97 \\
\hline 2 & 100 & 2430.56 & $\mathrm{CCW}$ & 497.29 \\
\hline 3 & 90 & 2562.5 & $\mathrm{CW}$ & 524.28 \\
\hline 4 & 40 & 2527.77 & $\mathrm{CW}$ & 517.18 \\
\hline
\end{tabular}

network Along with tracking error rates.

Table 1.0 (c). Illustrations the value of the angles 1-layer

The value of the angles determined for the joints in degrees, along with the strength of the potentiometers of the joints and their corresponding digital values for tracking the path No. 2 under the influence of the 1-layer network Along with tracking error rates.

\subsection{Path Number 2.0:}

The value of the angles determined for the joints in degrees, along with the strength of the potentiometers of the joints and their respective digital values for tracking path number 2.0.

Table 2.0(a). Illustrations the value of the angles 2-layer

\begin{tabular}{|l|l|l|l|l|}
\hline $\begin{array}{l}\text { Joi } \\
\text { nt }\end{array}$ & $\begin{array}{l}\text { Approxim } \\
\text { ate Angle } \\
\text { (degree) }\end{array}$ & $\begin{array}{l}\text { Potentiom } \\
\text { eter (Ohm) }\end{array}$ & $\begin{array}{l}\text { Digital } \\
\text { Approxim } \\
\text { ate }\end{array}$ & $\begin{array}{l}\text { Error } \\
\text { Approxm } \\
\text { ate }\end{array}$ \\
\hline 1 & 56.5 & 2310.83 & 467 & $7 \%$ \\
\hline 2 & 94 & 2284.72 & 462 & $7 \%$ \\
\hline 3 & 80 & 2255 & 461 & $12 \%$ \\
\hline 4 & 35.5 & 2224.43 & 455 & $12 \%$ \\
\hline
\end{tabular}

The value of the angles determined for the joints in degrees, along with the strength of the potentiometers of the joints and their corresponding digital values for tracking the path No. 2 under the influence of the 2-layer network Along with tracking error rates. 
Table 2.0(b) Illustrations the value of the angles 2-layer

\begin{tabular}{|l|l|l|l|l|}
\hline $\begin{array}{l}\text { Joi } \\
\text { nt }\end{array}$ & $\begin{array}{l}\text { Approximate } \\
\text { Angle } \\
\text { (degree) }\end{array}$ & $\begin{array}{l}\text { Potentiom } \\
\text { eter (Ohm) }\end{array}$ & $\begin{array}{l}\text { Digital } \\
\text { Approxi } \\
\text { mate }\end{array}$ & $\begin{array}{l}\text { Error } \\
\text { Approxim } \\
\text { ate }\end{array}$ \\
\hline 1 & 59.5 & 2433.74 & 497 & $1 \%$ \\
\hline 2 & 99 & 2406.25 & 492 & $1 \%$ \\
\hline 3 & 89 & 2536.87 & 519 & $1 \%$ \\
\hline 4 & 39.5 & 2502.49 & 512 & $1 \%$ \\
\hline
\end{tabular}

Table 2.0(c) Illustrations the value of the angles 2-layer

\begin{tabular}{|l|l|l|l|l|}
\hline $\begin{array}{l}\text { Joi } \\
\text { nt }\end{array}$ & $\begin{array}{l}\text { Approxim } \\
\text { ate Angle } \\
\text { (degree) }\end{array}$ & $\begin{array}{l}\text { Potentiom } \\
\text { eter } \\
\text { (Ohm) }\end{array}$ & $\begin{array}{l}\text { Digital } \\
\text { (Approxim } \\
\text { ate) }\end{array}$ & $\begin{array}{l}\text { Error } \\
\text { (Approxim } \\
\text { ate) }\end{array}$ \\
\hline 1 & 29.7 & 2495.62 & 510 & $1 \%$ \\
\hline 2 & 49.5 & 2440.62 & 499 & $1 \%$ \\
\hline 3 & 69.3 & 2426.87 & 496 & $1 \%$ \\
\hline 4 & 59.4 & 2433.75 & 497 & $1 \%$ \\
\hline
\end{tabular}

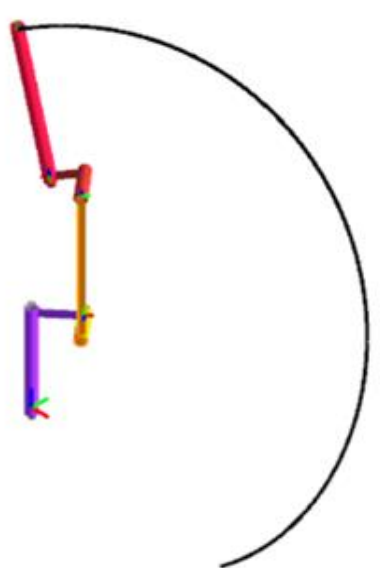

Figure 5(a): Simulation of tracking the No.2 specified path without error by the robot, by applying a 1-layer and 2-layer neural network.

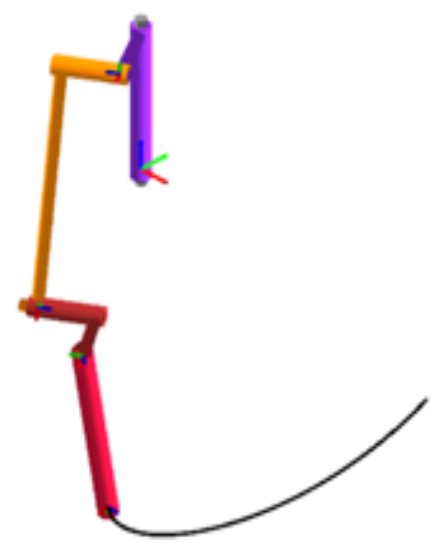

Figure 5(b): Simulation of tracking the No.1 specified path without error by the robot, by applying a 1-layer and 2-layer neural network.

\section{TEST}

Considering the values in the above tables related to robot motion feedback, the angle of joints in terms of degrees and the values of potentiometers attached to the shaft joints, and the study of the performance of the MLP network in both single-layer and two-layer modes for the two different paths we concluded In this technique, the more number of layers in the grid is, the more accurate the robot's performance is seen in the training path and the less error. When the joints involved in the training movement on the robot have a large variation of the values by angles. The robot has a greater error in the repetition of the learned motion in the joints near the base of the robot, due to the inability to control and hold the joints at the desired angle with the help of the operator by the operator in the process of their simultaneous movement in training. The simulation result is shown to us when the robot performs combinational motions involving several joint periods simultaneously, with a higher error rate than the movements required to run a path in sequence. The results of the above tests are related to the simultaneous motion and the sequential movement tables for both paths are shown in the table below (Table 3) and practically have a very slight error in all cases. For this reason, we solve the problem of repeatability error in the process of tracking the paths by simultaneously moving the network joints into two layers and five inputs, and the result is presented in Table 1 (c) and Table 2 (c). The accuracy of the network in two modes is the path of number 1 and path No. 2 under the influence of the twolayer network in both consecutive and simultaneous motion of the joints and the error is close to zero.

\section{RESULTS}

The results of the test of track path No.1.0 and path No. 2.0 in the mode of sequential movement of joints, influenced by the network of 1 layer and 2 layers with error detection as illustrates in table 3.0. 
And the results from the linear regression network designed in this project, implemented in Weka software, and the general characteristics of the network, as illustrates in Table 4.0 both ( $\mathrm{a}$ and $\mathrm{b}$ ). During system testing.

Table 3.0. Illustrations the value of the angles for both Path No.1.0 and Path No.2.0.

\begin{tabular}{|c|c|c|c|}
\hline Joint & \multicolumn{2}{|c|}{$\begin{array}{l}\text { Network } \\
\text { Layer }\end{array}$} & $\begin{array}{l}\text { Error in } \\
\text { percent } \\
\text { (Approximate) }\end{array}$ \\
\hline \multicolumn{4}{|c|}{ Path No.1.0 } \\
\hline \multirow[t]{2}{*}{1} & \multirow[t]{2}{*}{${ }^{\circ} 30$} & $\begin{array}{l}\text { One- } \\
\text { layer }\end{array}$ & 1 \\
\hline & & $\begin{array}{l}\text { Two- } \\
\text { layer }\end{array}$ & 1 \\
\hline \multirow[t]{2}{*}{2} & \multirow[t]{2}{*}{${ }^{\circ} 50$} & $\begin{array}{l}\text { One- } \\
\text { layer }\end{array}$ & 1.23 \\
\hline & & $\begin{array}{l}\text { Two- } \\
\text { layer }\end{array}$ & 1 \\
\hline \multirow[t]{2}{*}{3} & \multirow[t]{2}{*}{${ }^{\circ} 70$} & $\begin{array}{l}\text { One- } \\
\text { layer }\end{array}$ & 1.35 \\
\hline & & $\begin{array}{l}\text { Two- } \\
\text { layer }\end{array}$ & 1 \\
\hline \multirow[t]{2}{*}{4} & \multirow[t]{2}{*}{${ }^{\circ} 60$} & $\begin{array}{l}\text { One- } \\
\text { layer }\end{array}$ & 1.30 \\
\hline & & $\begin{array}{l}\text { Two- } \\
\text { layer }\end{array}$ & 1 \\
\hline \multicolumn{4}{|c|}{ Path No.2.0 } \\
\hline \multirow[t]{2}{*}{1} & \multirow[t]{2}{*}{${ }^{\circ} 60$} & $\begin{array}{l}\text { One- } \\
\text { layer }\end{array}$ & 1.3 \\
\hline & & $\begin{array}{l}\text { Two- } \\
\text { layer }\end{array}$ & 1 \\
\hline \multirow[t]{2}{*}{2} & \multirow[t]{2}{*}{$\begin{array}{l}{ }^{\circ} 10 \\
0\end{array}$} & $\begin{array}{l}\text { One- } \\
\text { layer }\end{array}$ & 1.5 \\
\hline & & $\begin{array}{l}\text { Two- } \\
\text { layer }\end{array}$ & 1 \\
\hline \multirow[t]{2}{*}{3} & \multirow[t]{2}{*}{${ }^{\circ} 90$} & $\begin{array}{l}\text { One- } \\
\text { layer }\end{array}$ & 1.4 \\
\hline & & $\begin{array}{l}\text { Two- } \\
\text { layer }\end{array}$ & 1 \\
\hline \multirow[t]{2}{*}{4} & \multirow[t]{2}{*}{${ }^{\circ} 40$} & $\begin{array}{l}\text { One- } \\
\text { layer }\end{array}$ & 1 \\
\hline & & $\begin{array}{l}\text { Two- } \\
\text { layer }\end{array}$ & 1 \\
\hline
\end{tabular}

Table 4.0 (a).

$===$ Run information $===$

Scheme: Weka classifiers functions Linear

Regression -S 0 -R 1.0E-8

Relation: Data new

Instances: 271

Attributes: 2

rotation

output

Test mode: 10-fold cross-validation

$===$ Classifier model (full training set) $===$

Linear Regression Model

output $=$
$3.789 *$ rotation +
0.0078

Time taken to build model: 0.01 seconds

$===$ Cross-validation $===$

$===$ Summary $===$

Correlation coefficient

Mean absolute error

1

Root mean squared error

Relative absolute error

Root relative squared error

Total Number of Instances

$0.097 \%$

271

Table 4.0 (b).

=== Run information $===$
Scheme: Weka classifiers functions Linear Regression
-S 0 -R 1.0E-8
Relation: Data new
Instances: 271
Attributes: 2
$\quad$ rotation
$\quad$ output
Test mode: 10 -fold cross-validation
$===$ Classifier model (full training set) $===$
Linear Regression Model
output =
$\quad 3.789 *$ rotation +
$\quad 0.0078$
Time taken to build model: 0.01 seconds
=== Cross-validation ===
$===$ Summary ===
Correlation coefficient
Mean absolute error
Root mean squared error
Relative absolute error
Root relative squared error
Total Number of Instances




\section{CONCLUTION}

Using the MLP Linear Regression Neural Network in both 1-layer and 2-layer modes, according to one-handed data, shows that in the case of a 2-layer network, the error rate of the network output and the encoders are 1layer in a reasonable amount. The attention has been diminished and much less time has been taken to optimize and run the route.

\section{RECOMMENDATION}

The recommendation for improving the performance of this arm control system for timely, operational and economic reasons:

1. Use of high-frequency processors such as ARM Controller.

2. Use of external A / D circuits with a resolution of 24 bits.

3. Use of electric actuators of permanent magnet motors of DC motors. 4. Use of work space calculations along with joint analysis and implementation of base model controllers 5. Simultaneous use and integration of the machine vision control method with the method presented in this paper work for controlling the arm for greater stability.

\section{REFERENCE}

[1]. Edited by Rudolf Traub-Merz. (2017)Published by: Friedrich-Ebert-Stiftung, Hiroshimastraße 28, 10785 Berlin, and ISBN: 978-3-95861-597-7 [Online] available from: http://library.fes.de/pdffiles/iez/13154.pdf.

[2]. T. SALIH, OMAR and YEHEA O., (2014). "an alternative solution for controlling robotic arm using FPAA technology" [Online] available from: www.jatit.org/volumes/researchpapers/Vol28No1/6Vol28No1.pdf

[3]. Y. Asano, et. al. (2012). "“'Lower thigh design of detailed musculoskeletal humanoid

[4]. "Kenshiro"', In Proc. IEEE/RSJ International Conference on Intelligent Robots and Systems

[5]. IROS, pages 4367-4372, Oct. 2012. ISBN 978-14673-1736-8. doi: 10.1109/IROS.2012. 6386225.

[6]. K. Hosoda, et. al. (2012). "Anthropomorphic Muscular-Skeletal Robotic Upper Limb for Understanding Embodied Intelligence". Advanced Robotics, 26(7):729-744.

[7]. M. Jäntsch, et. al. (2013)." Anthrob - A Printed Anthropomimetic Robot". In Proceedings of the IEEE-RAS International Conference on Humanoid Robots (Humanoids).

[8]. K. Kaltsoukalas, et al., (April 2015). "Robotics and Computer-Integrated Manufacturing On generating the motion of industrial robot manipulators", Elsevier (Robotics and Computer-Integrated Manufacturing Volume 32, Pages 65-71.
[9]. F. Nadi, Vali Derhami, Mehdi Rezaeian, (Summer 2014). "Vision Based Robot Manipulator Control with Neural Modeling of Jacobian Matrix matrix estimation", Journal of Control, Vol. 8, No. 2.

[10]. S.M. Ahmadi, M.M. Fateh, (2014). "Robust control of electrically driven robots using control system", Journal of Solid and Fluid Mechanics, 4(3) 11-21, 2014 (In Persian). .... [88] M. M. Fateh, Variable structure fuzzy-linear force control of robot, Journal of.

[11]. A. Vijayan*Amrita School of Biotechnology , Hareesh Singanamala*Amrita School of Biotechnology IEEE 2013 Asha Vijayan, Chaitanya Nutakki, Chaitanya Medini, Hareesh Singanamala, Dr. Bipin G. Nair, Krishnasree Achuthan, and Dr. Shyam Diwakar, (2013)., "Classifying Movement Articulation for Robotic Arms via Machine Learning", Journal of Intelligent Computing, IEEE, vol. 4, no. 3, pp. 123-134.

[12].A. Vijayan, Chaitanya Nutakki, Dhanush Kumar, Dr. Krishnashree Achuthan, Dr. Bipin G. Nair, and Dr. Shyam Diwakar, (2017)., "Enabling a freely accessible open source remotely controlled robotic articulator with a neuro-inspired control algorithm", International Journal of Interactive Mobile Technologies, vol. 13, no. 1, pp. 61-75.

[13].P.K.Panigrahi, Saradindu Ghosh, Dayal R Parhi, (June 2014)., "Intelligent Leaning and Control of Autonomous Mobile Robot using MLP and RBF based Neural Network in Clustered Environment", International Journal of Scientific \& Engineering Research, Volume 5, Issue 6. 
